\title{
Predictive factors for sentinel node metastases in primary invasive breast cancer: a population-based cohort study of 2552 consecutive patients
}

Shabaz Majid ${ }^{1,2^{*}}$ (D) Lisa Rydén ${ }^{3,4}$ and Jonas Manjer ${ }^{2,3}$

\begin{abstract}
Background: Axillary lymph node status is one of the most important prognostic factors for breast cancer. The aim of this study was to determine predictive factors for metastasis to sentinel node (SN) in primary invasive breast cancer.

Method: This is a study of 3979 patients with primary breast cancer during 2008-2013 in Malmö and Lund scheduled for surgery and included in the information retrieved from Information Network for Cancer Care (INCA). The final study population included 2552 patients with primary invasive breast cancer. The risk of metastases to SN were examined in relation to potential clinicopathological factors such as age, screening mammography, tumor size, tumor type, histological grade, estrogen status, progesterone status, Her-2 status, multifocality, and lymphovascular invasion. Binary logistic regression was used; adjusted analyses yielded odds ratio (OR) with 95\% confidence interval.

Results: Tumors detected by mammography screening were less likely to be associated with metastases to SN compared to those not found by mammography screening $(0.63 ; 0.51-0.80)$. Negative hormonal status for estrogen associated with lower risk for SN metastases compared to tumor with positive estrogen status (0.64; 0.42-0.99). Tumors with a size more than $20 \mathrm{~mm}$ had higher risk to metastasize to SN $(1.84 ; 1.47-2.33)$ compared to tumors less than $20 \mathrm{~mm}$. Multifocality (1.90; 1.45-2.47) and lymphovascular invasion (3.74; $2.66-5.27)$ were also strong predictive factors for SN metastases.

Conclusion: SN metastasis is less likely to occur in women with invasive breast cancer diagnosed by screening mammogram. Tumors with negative estrogen status are associated with low risk for SN metastases. Tumors larger than $20 \mathrm{~mm}$, multifocality, or lymphovascular invasion are also factors associated with high risk for SN metastases.
\end{abstract}

Keywords: Invasive breast cancer, Predictive factors, Sentinel node metastases

\section{Background}

Axillary lymph node status is still one of the most important prognostic factors for predicting clinical outcome in invasive breast cancer [1,2], and it also determines the extent of axillary surgery and adjuvant/systemic therapy. Recently, the value of an axillary clearance when metastatic spread is found has been questioned [3,4]. Indeed, it may be questioned if staging is necessary in all cases, e.g., even in

\footnotetext{
* Correspondence: shabaz.majid@med.lu.se

'Department of Surgery, Central Hospital of Kristianstad, SE-291 85 Kristianstad, Sweden

${ }^{2}$ Department of Clinical Sciences Malmö, Lund University, Malmö, Sweden Full list of author information is available at the end of the article
}

patients where the risk of metastatic spread is very low. However, this demands that low-risk groups can be accurately identified [5].

Physical examination is a poor predictor of axillary lymph node metastasis [6], and evaluation of the axilla by ultrasound has been shown to be unreliable [7].

Sentinel node biopsy (SNB) has been used since the late 1990s to evaluate the axillary lymph node status [1]. The sentinel lymph node is defined as the first lymph nodes to which cancer cells are most likely to spread from the primary tumor. SNB has minimized the need for axillary lymph node dissection (ALND) dramatically which in turn decreases the subsequent complications 
after ALND such as lymphedema, chronic pain, and neurological disabilities $[8,9]$. Many studies have confirmed that SNB is technically feasible, safe, and associated with fewer complications as compared with ALND [1, 2, 9]. However, the $\mathrm{SNB}$ as a process is time consuming and resource intensive and, in the majority of patients, SNs are without metastases, and although the SNB is associated with fewer complications, there is still a risk to develop disabilities postoperatively $[9,10]$. The proportion of $\mathrm{T} 1$ invasive breast carcinomas is increasing due to factors such as better diagnostic methods and public screening programs, and the role of SNB and ALND in these patients has been questioned $[3,11,12]$.

The aim of this study was to define clinical and pathological factors that predict patients who are likely to be node-positive and thus to have the possibility for better planning of surgical or systemic therapy. Moreover, the information can enable the identification of patients with a high probability of node-negative tumor where the SN procedure may possibly be omitted.

\section{Methods}

The background population consists of all cases of breast cancer among women in Lund and Malmö operated on between January 2008 and December 2013. Every patient was identified by a 12-digit civil registration number which is unique for every Swedish citizen. All patients operated on because of breast cancer were included, and a total number of 3979 cases (cancer events) were identified. The indication for SNB has been changed over the time; in the early beginning of 2000s, the SNB procedure was performed only when tumor size was smaller than $30 \mathrm{~mm}$ and all cases with tumor size larger than $30 \mathrm{~mm}$ as well as multifocal tumors underwent ALND directly in both centers.

The following patients were excluded: 30 male patients, 82 cases with bilateral breast cancer (that is, 164 cancer events), 43 cases with previous breast cancer, and 1040 cases who were not operated on with SNB; 122 cases were diagnosed with in situ breast cancer and 25 patients who had received systemic therapy preoperatively. In two patients, it was not known if they had received systemic therapy, and one patient had unknown information about SN status. Regarding those cases not operated on with SNB (1040 patients), there were 599 who underwent an axillary dissection; 191 women had neither underwent SNB nor an ALND, and information on axillary surgery was missing in the remaining 250 patients.

In the 1040 excluded patients, $48.5 \%$ had tumors that were stage T2 or above; among ALND operated cases, this percentage was 35.3\%; and in women with neither SNB nor ALND was $1.25 \%$. The corresponding percentage in our study population of 2552 patients was $22.8 \%$.
Furthermore, among all 1040 excluded patients, 18.7\% had a multifocal tumor. In ALND cases, this proportion was $16.7 \%$; in patients with no surgery in the axilla, it was $1.8 \%$; and in our study population, it was $13.8 \%$. Following these exclusions, the final study population included 2552 patients (Fig. 1).

In Sweden, a nationwide database for breast cancer is available on an IT platform called The Information Network for Cancer Care (INCA). INCA manages various information about cancer care as well as long-term follow-up. It is run and developed jointly by the country's regional cancer centers. INCA has been in full operation since 2007. The Regional Cancer Center in Southern Sweden (RCC-Syd) is the main center in the southern area which manages this registry.

In Malmö and Lund at Skåne University Hospital, every patient with breast cancer is reviewed and discussed before and after surgery at a weekly multidisciplinary breast cancer conference at which there are representatives from the departments of oncology, radiology, surgery, and pathology. A special registration form designed by INCA is available, and this form is filled in by a surgeon in cooperation with a secretary who is specifically employed for this reason and who is responsible for entering the data into the platform. The present study was approved by the Ethic Committee at Lund University, Lund, Sweden (LU-Dnr 2013/821).

All information used in the present study such as screening, age, menopause status, tumor size, histopathological type and grade, receptor status, Her-2, multifocality, and lymphovascular invasion as well as information about SNB, i.e., type and size of metastases, were retrieved from INCA.

All women in the background population aged 4074 years are invited to the public mammography screening. Mode of detection was recorded as screening-detected yes/no. Menopause status was defined as premenopausal or postmenopausal.

Postmenopausal women were subdivided as to when they had their last menstruation, 6 months to 5 years ago or more than 5 years after menopause. Tumor size was defined according to the TNM classification, T1 tumor $\leq 20 \mathrm{~mm}$, T2 tumor $21-50 \mathrm{~mm}$, and T3-T4 $>50 \mathrm{~mm}$. [13]. The $\mathrm{T} 1$ tumors were further classified to subgroups T1a 1-5 mm, T1b 6-10 mm, and T1c 11-20 mm. The histopathological types were classified according to the WHO classification system; this system describes mainly six different histopathological types of invasive cancer [13-15]. We merged this into four different groups, i.e., ductal, lobular, combined ductal with lobular, and other rare types. Histological grade was defined according to the Nottingham histological grading (NHG) [16]. Multifocal tumors were defined as two or more tumors with normal tissue or in situ tumors at a distance of at least $20 \mathrm{~mm}$. Lymphovascular invasion is defined 


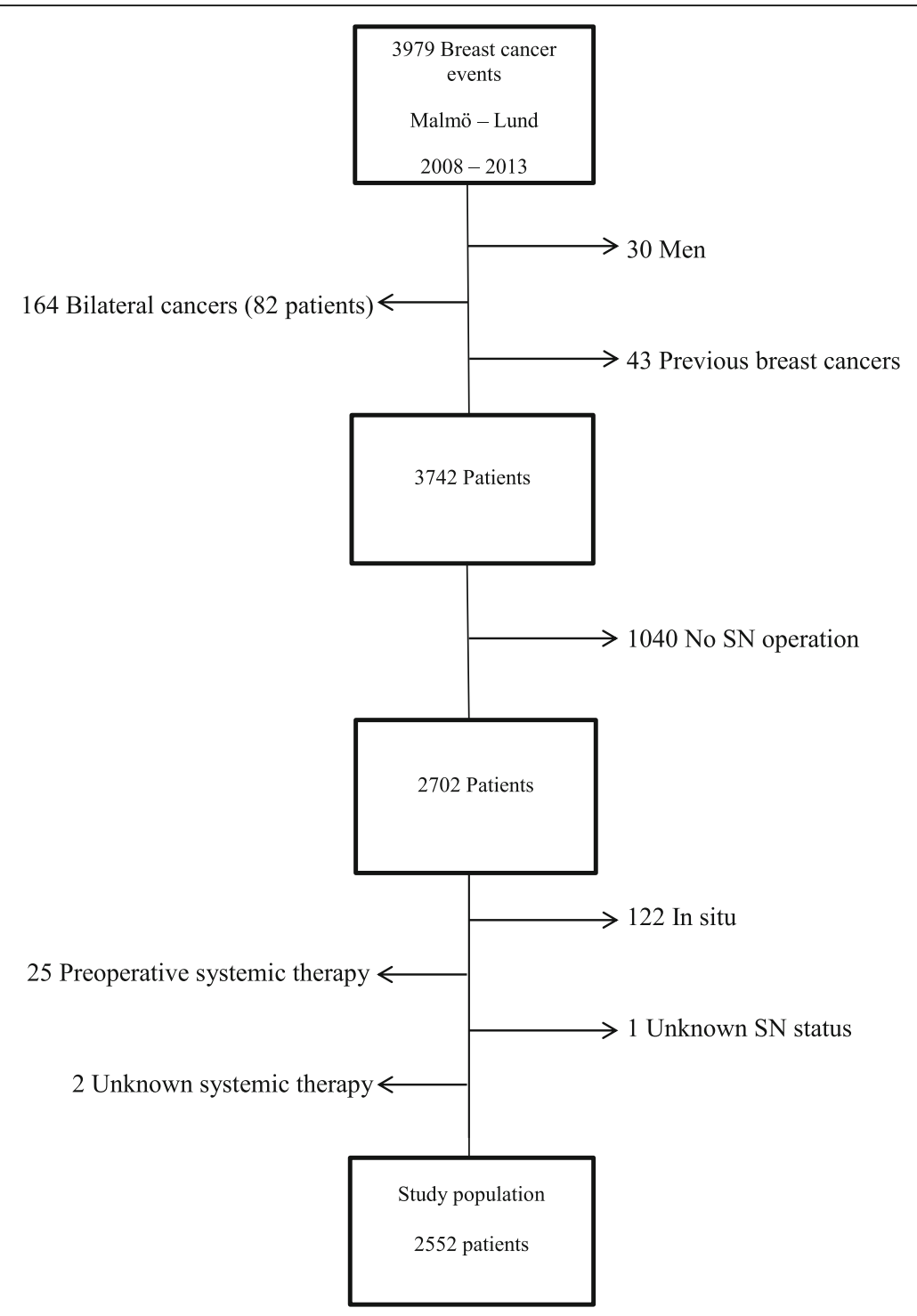

Fig. 1 Patient selection

as tumor cells in vascular spaces, tumor cells in underlying endothelium of vascular channels, and tumor cells invading through a vessel wall and endothelium [17]. Receptor status for both estrogen and progesterone was measured by immunohistochemistry (IHC). Receptor percentage more than $10 \%$ was regarded as positive and those with $10 \%$ or less as negative [18]. Her-2 protein was analyzed with $\mathrm{IHC}$, and test results were reported as $0,1+, 2+$, or 3 + . Fluorescent in situ hybridization (FISH) uses fluorescent pieces of DNA that specifically stick to copies of the HER2 gene in cells. In all cases, IHC test was used first and then completed by FISH in certain cases where Her- 2 was $2+$ or $3+$. Her- 2 status was classified as negative when Her-2 $\mathrm{IHC}=0-1+$ and $2+$ in non-amplified tumors. Her-2 was regarded as positive if Her-2 was classified as $2+$ or $3+$ and amplified by FISH [19]

Metastases in SN were classified as macrometastases when the size was $>2 \mathrm{~mm}$ and regarded as micrometastases when the size was $0.2-2.0 \mathrm{~mm}$. All metastases with a size less than $0.2 \mathrm{~mm}$ were regarded as sub-micrometastases. Lymph nodes with only sub-micrometastases also referred to as isolated tumor cells (ITCs) were regarded as without metastases in the present analysis [18].

Lymph nodes with macro- or micrometastases were regarded as positive and those without metastases as negative. To compare the association between potential predictive factors and metastases in SN, binary logistic regression was used and all analyses were adjusted for all included factors, i.e., screening, age, tumor size, menstrual status, histopathological type and grade, receptor 
status for estrogen and progesterone, Her-2 status, presence of multifocality, and presence of vascular invasion. This yielded odds ratios (ORs) with 95\% confidence intervals (CIs). Main analyses were performed for the two centers together, center A (Lund) and center B (Malmö). Moreover, the analyses were also performed for each center separately. Statistical Package for the Social Sciences (SPSS) program version 22.0 (SPSS Institute, Chicago, IL, USA) was used for all analyses.

\section{Results}

There were in total 671 patients with SN metastases (26.3\%), three hundred seventy four patients $(29.6 \%)$ in center A and 297 patients (23.0\%) in center B. Tumors detected by mammography screening were less likely to be associated with SN metastases compared with those not found by screening mammography $(0.63 ; 0.51-0.80)$, Tables 1 and 2. A tumor with a size more than $20 \mathrm{~mm}$, i.e., T2, T3, and T4, had higher possibility to metastasize to the SN compared to tumors less than $20 \mathrm{~mm}$ (T1): 1.84 and $1.47-2.33$ for T2 and 2.56 and $1.07-6.09$ for T3 and T4. An additional analysis showed that T1a tumors had the lowest risk for SN metastases $(0.19 ; 0.09-0.40)$ followed by T1b $(0.46 ; 0.34-0.63)$ compared with T1c.

A negative association with $\mathrm{SN}$ metastases was seen in cases with negative hormonal status for estrogen (0.64; $0.42-0.99)$. Multifocal tumors $(1.90 ; 1.45-2.47)$ or tumors with vascular invasion $(3.74 ; 2.66-5.27)$ had higher risk of SN metastases. Tumor types other than ductal and lobular, i.e., medullary and other rare types, were associated with low risk for SN metastases (0.29; 0.18-0.46). Adjusted analyses were similar to crude values except for histological grade II and III where crude analyses were associated with higher risk for SN metastases, but this was not observed with adjusted analyses. Overall, there were no large differences in results between the two centers; however, the risk of metastases to $\mathrm{SN}$ in all T3 and T4 cases were not high in center B while in center A there was a high risk of $\mathrm{SN}$ metastases in T3 and T4 cases (Table 3). In all analyses, there was no statistical significance in different histological grades in both centers, and hormonal status was not statistically significant when we analyzed each center separately. These analyses included few cases and CI was relatively wide.

\section{Discussion}

In this study, we identified predictive factors for $\mathrm{SN}$ metastases by analyzing clinical and pathological characteristics of the tumors in patients with primary invasive breast cancer, and we found that $\mathrm{SN}$ metastasis is less likely to occur in women diagnosed by screening mammography. Tumors with negative estrogen status were associated with low risk of SN metastases. Tumors
Table 1 Potential predictive factors in relation to SN status

\begin{tabular}{|c|c|c|c|c|c|c|}
\hline \multirow[t]{2}{*}{ Determinants } & \multirow[t]{2}{*}{ Category } & \multirow[t]{2}{*}{ Total } & \multicolumn{2}{|c|}{ SN negative } & \multicolumn{2}{|c|}{ SN positive } \\
\hline & & & $N$ & $\%$ & $N$ & $\%$ \\
\hline \multirow[t]{3}{*}{ Screening } & No & 1062 & 719 & 38.2 & 343 & 51.1 \\
\hline & Yes & 1435 & 1123 & 59.7 & 312 & 46.5 \\
\hline & Unknown & 55 & 39 & 2.1 & 16 & 2.4 \\
\hline \multirow[t]{3}{*}{ Age } & $\leq 50$ & 499 & 337 & 17.9 & 162 & 24.1 \\
\hline & $51-74$ & 1702 & 1290 & 68.6 & 412 & 61.4 \\
\hline & $\geq 75$ & 351 & 254 & 13.5 & 97 & 14.5 \\
\hline \multirow[t]{4}{*}{ Menopause status } & Pre & 512 & 348 & 18.5 & 164 & 24.4 \\
\hline & Post $<5$ years & 228 & 168 & 8.9 & 60 & 8.9 \\
\hline & Post $\geq 5$ years & 1721 & 1299 & 69.1 & 422 & 62.9 \\
\hline & Unknown & 91 & 66 & 3.5 & 25 & 3.7 \\
\hline \multirow[t]{4}{*}{ Tumor size } & $\mathrm{T} 1$ & 1505 & 1138 & 60.5 & 367 & 54.7 \\
\hline & $\mathrm{T} 2$ & 559 & 346 & 18.4 & 213 & 31.7 \\
\hline & $\mathrm{T} 3$ and $\mathrm{T} 4$ & 25 & 13 & 0.7 & 12 & 1.8 \\
\hline & Unknown & 463 & 384 & 20.4 & 79 & 11.8 \\
\hline \multirow[t]{4}{*}{ Tumor type } & Ductal & 1866 & 1324 & 70.4 & 542 & 80.8 \\
\hline & $D$ and $L$ & 52 & 35 & 1.9 & 17 & 2.5 \\
\hline & Lobular & 304 & 216 & 11.5 & 88 & 13.1 \\
\hline & Other & 330 & 306 & 16.3 & 24 & 3.6 \\
\hline \multirow[t]{4}{*}{ Histological grade } & I & 622 & 488 & 25.9 & 134 & 20.0 \\
\hline & $\|$ & 1112 & 807 & 42.9 & 305 & 45.5 \\
\hline & III & 790 & 563 & 29.9 & 227 & 33.8 \\
\hline & Unknown & 28 & 23 & 1.2 & 5 & 0.7 \\
\hline \multirow[t]{3}{*}{ Estrogen receptor } & Positive & 2144 & 1538 & 81.8 & 606 & 90.3 \\
\hline & Negative & 279 & 218 & 11.6 & 61 & 9.1 \\
\hline & Unknown & 129 & 125 & 6.6 & 4 & 0.6 \\
\hline \multirow[t]{3}{*}{ Progesterone receptor } & Positive & 1851 & 1320 & 70.2 & 531 & 79.1 \\
\hline & Negative & 571 & 436 & 70.2 & 531 & 79.1 \\
\hline & Unknown & 130 & 125 & 6.6 & 5 & 0.7 \\
\hline \multirow[t]{3}{*}{ HER-2 status } & Negative & 1466 & 1041 & 55.3 & 423 & 63.0 \\
\hline & Positive & 240 & 174 & 9.3 & 66 & 9.8 \\
\hline & Unknown & 848 & 666 & 35.4 & 182 & 27.1 \\
\hline \multirow[t]{3}{*}{ Multifocality } & No & 1570 & 1184 & 62.9 & 386 & 57.5 \\
\hline & Yes & 352 & 208 & 11.1 & 144 & 21.5 \\
\hline & Unknown & 630 & 489 & 26.0 & 141 & 21.0 \\
\hline \multirow[t]{3}{*}{ Vascular invasion } & No & 1324 & 1056 & 56.1 & 268 & 39.9 \\
\hline & Yes & 184 & 87 & 4.6 & 97 & 14.5 \\
\hline & Unknown & 1044 & 738 & 39.2 & 306 & 45.6 \\
\hline
\end{tabular}

with a size more than $20 \mathrm{~mm}$, multifocality, or lymphovascular invasion had more risk for $\mathrm{SN}$ metastases.

The strengths of the present study include the size of the sample, where 3979 patients with breast cancer were included from a non-selected population-based cohort of consecutive cases. Those patients who did 
Table 2 Potential predictive factors and risk of SN metastases

\begin{tabular}{|c|c|c|c|c|c|}
\hline Determinants & Category & SN negative & SN positive & OR 95\% Cl & OR 95\% $\mathrm{Cl}^{\mathrm{a}}$ \\
\hline \multirow[t]{3}{*}{ Screening } & No & 719 & 343 & 1.00 & 1.00 \\
\hline & Yes & 1123 & 312 & $0.59(0.49-0.70)$ & $0.63(0.51-0.80)$ \\
\hline & Unknown & 39 & 16 & $0.86(0.48-1.57)$ & $0.88(0.46-1.66)$ \\
\hline \multirow[t]{3}{*}{ Age } & $\leq 50$ & 337 & 162 & 1.00 & 1.00 \\
\hline & $51-74$ & 1290 & 412 & $0.67(0.53-0.82)$ & $0.92(0.63-1.37)$ \\
\hline & $\geq 75$ & 254 & 97 & $0.80(0.59-1.08)$ & $0.70(0.42-1.11)$ \\
\hline \multirow[t]{4}{*}{ Menopause Status } & Pre & 348 & 164 & 1.00 & 1.00 \\
\hline & Post $<5$ years & 168 & 60 & $0.76(0.53-1.08)$ & $0.98(0.62-1.53)$ \\
\hline & Post $\geq$ 5years & 1299 & 422 & $0.69(0.56-0.86)$ & $0.82(0.56-1.22)$ \\
\hline & Unknown & 66 & 25 & $0.80(0.49-1.32)$ & $0.89(0.50-1.53)$ \\
\hline \multirow[t]{4}{*}{ Tumor size } & $\mathrm{T} 1$ & 1138 & 367 & 1.00 & 1.00 \\
\hline & $\mathrm{T} 2$ & 346 & 213 & $1.91(1.56-2.34)$ & $1.84(1.47-2.33)$ \\
\hline & $\mathrm{T} 3$ and $\mathrm{T} 4$ & 13 & 12 & $2.87(1.30-6.32)$ & $2.56(1.07-6.09)$ \\
\hline & Unknown & 384 & 79 & $0.63(0.49-0.83)$ & $0.67(0.50-0.93)$ \\
\hline \multirow[t]{4}{*}{ Tumor type } & Ductal & 1325 & 542 & 1.00 & 1.00 \\
\hline & $\mathrm{D}$ and $\mathrm{L}$ & 35 & 17 & $1.19(0.66-2.13)$ & $1.01(0.54-1.90)$ \\
\hline & Lobular & 217 & 88 & $1.00(0.77-1.30)$ & $0.87(0.64-1.20)$ \\
\hline & Others & 306 & 24 & $0.20(0.12-0.30)$ & $0.29(0.18-0.46)$ \\
\hline \multirow[t]{4}{*}{ Histological grade } & । & 488 & 134 & 1.00 & 1.00 \\
\hline & $\|$ & 807 & 305 & $1.37(1.09-1.73)$ & $1.02(0.80-1.31)$ \\
\hline & III & 563 & 227 & $1.46(1.14-1.87)$ & $1.10(0.82-1.50)$ \\
\hline & Unknown & 23 & 5 & $0.79(0.29-2.12)$ & $1.40(0.46-4.31)$ \\
\hline \multirow[t]{3}{*}{ Estrogen receptor } & Positive & 1538 & 606 & 1.00 & 1.00 \\
\hline & Negative & 218 & 61 & $0.71(0.52-0.96)$ & $0.64(0.42-0.99)$ \\
\hline & Unknown & 125 & 4 & $0.09(0.03-0.22)$ & $0.06(0.00-0.82)$ \\
\hline \multirow[t]{3}{*}{ Progesterone receptor } & Positive & 1320 & 531 & 1.00 & 1.00 \\
\hline & Negative & 436 & 135 & $0.77(0.61-0.96)$ & $0.78(0.56-1.07)$ \\
\hline & Unknown & 125 & 5 & $0.10(0.04-0.24)$ & $3.80(0.30-47.42)$ \\
\hline \multirow[t]{3}{*}{ Her-2 status } & Negative & 1041 & 423 & 1.00 & 1.00 \\
\hline & Positive & 174 & 66 & $0.93(0.69-1.27)$ & $0.84(0.60-1.20)$ \\
\hline & Unknown & 666 & 182 & $0.68(0.56-0.82)$ & $0.98(0.78-1.24)$ \\
\hline \multirow[t]{3}{*}{ Multifocality } & No & 1184 & 386 & 1.00 & 1.00 \\
\hline & Yes & 208 & 144 & $2.12(1.67-2.70)$ & $1.90(1.45-2.47)$ \\
\hline & Unknown & 489 & 141 & $0.89(0.71-1.10)$ & $0.86(0.67-1.09)$ \\
\hline \multirow[t]{3}{*}{ Vascular invasion } & No & 1056 & 268 & 1.00 & 1.00 \\
\hline & Yes & 87 & 97 & $4.40(3.20-6.04)$ & $3.74(2.66-5.27)$ \\
\hline & Unknown & 738 & 306 & $1.63(1.36-1.98)$ & $2.10(1.68-2.62)$ \\
\hline
\end{tabular}

${ }^{a}$ Adjusted including screening, age, menopause status, tumor size, tumor type, histological grade, estrogen status, progesterone status, Her-2 status, multifocality, and vascular invasion

not undergo SNB procedure and were excluded in final study population, they were mainly divided into two groups, carcinoma in situ and advanced invasive tumors where majority were $\mathrm{T} 2$ tumors. The reliability of collected data and accuracy of registration might be questioned; however, the quality of the INCA registry is regarded as very high with periodic validation control of data recording [20].

Assessment of axillary lymph status is essential because it predicts the clinical outcome and it also determines the extent of axillary surgery and adjuvant/systemic therapy. Node-negative patients do not benefit from axillary surgery, 
Table 3 Potential predictive factors and risk of SN metastases separately for center A and center B

\begin{tabular}{|c|c|c|c|c|c|c|c|}
\hline \multirow[t]{2}{*}{ Determinants } & \multirow[t]{2}{*}{ Category } & \multicolumn{3}{|l|}{ Center A } & \multicolumn{3}{|l|}{ Center B } \\
\hline & & SN positive & SN negative & OR 95\% Cl & SN positive & SN negative & OR 95\% Cl \\
\hline \multirow[t]{3}{*}{ Screening } & No & 297 & 179 & 1.00 & 422 & 164 & 1.00 \\
\hline & Yes & 552 & 179 & $0.62(0.46-0.86)$ & 571 & 133 & $0.63(0.47-0.88)$ \\
\hline & Unknown & 39 & 16 & $0.82(0.42-1.60)$ & - & - & - \\
\hline \multirow[t]{3}{*}{ Age } & $\leq 50$ & 157 & 86 & 1.00 & 180 & 76 & 1.00 \\
\hline & $51-74$ & 620 & 237 & $1.02(0.59-1.78)$ & 670 & 175 & $0.82(0.48-1.44)$ \\
\hline & $\geq 75$ & 111 & 51 & $0.69(0.34-1.39)$ & 143 & 46 & $0.69(0.34-1.37)$ \\
\hline \multirow[t]{4}{*}{ Menopause status } & Pre & 167 & 90 & 1.00 & 181 & 74 & 1.00 \\
\hline & Post $<5$ years & 91 & 29 & $0.67(0.34-1.29)$ & 77 & 31 & $1.32(0.70-2.50)$ \\
\hline & Post $\geq 5$ years & 589 & 238 & $0.88(0.50-1.52)$ & 710 & 184 & $0.77(0.43-1.34)$ \\
\hline & Unknown & 41 & 17 & $0.81(0.40-1.67)$ & 25 & 8 & $0.87(0.34-2.16)$ \\
\hline \multirow[t]{4}{*}{ Tumor size } & $\mathrm{T} 1$ & 394 & 191 & 1.00 & 744 & 176 & 1.00 \\
\hline & $\mathrm{T} 2$ & 136 & 105 & $1.63(1.16-2.30)$ & 210 & 108 & $2.13(1.54-2.94)$ \\
\hline & $\mathrm{T} 3$ and $\mathrm{T} 4$ & 4 & 7 & $6.28(1.50-26.40)$ & 9 & 5 & $1.48(0.44-4.90)$ \\
\hline & Unknown & 354 & 71 & $0.60(0.42-0.84)$ & 30 & 8 & $1.70(0.72-4.04)$ \\
\hline \multirow[t]{4}{*}{ Tumor type } & Ductal & 620 & 306 & 1.00 & 704 & 236 & 1.00 \\
\hline & $\mathrm{D}$ and $\mathrm{L}$ & 25 & 12 & $0.89(0.42-1.88)$ & 10 & 5 & $1.20(0.38-3.79)$ \\
\hline & Lobular & 80 & 45 & $0.90(0.58-1.40)$ & 136 & 43 & $0.84(0.54-1.30)$ \\
\hline & Others & 163 & 11 & $0.23(0.11-0.50)$ & 143 & 13 & $0.30(0.17-0.57)$ \\
\hline \multirow[t]{4}{*}{ Histological grade } & I & 218 & 66 & 1.00 & 270 & 68 & 1.00 \\
\hline & $\|$ & 363 & 169 & $1.31(0.91-1.89)$ & 444 & 136 & $0.80(0.56-1.16)$ \\
\hline & III & 290 & 136 & $1.49(0.98-2.26)$ & 273 & 91 & $0.80(0.51-1.24)$ \\
\hline & Unknown & 17 & 3 & $1.30(0.31-5.37)$ & 6 & 2 & $2.38(0.36-15.87)$ \\
\hline \multirow[t]{3}{*}{ Estrogen receptor } & Positive & 679 & 335 & 1.00 & 859 & 271 & 1.00 \\
\hline & Negative & 98 & 35 & $0.59(0.33-1.04)$ & 120 & 26 & $0.72(0.38-1.40)$ \\
\hline & Unknown & 111 & 4 & $0.07(0.00-1.04)$ & 14 & - & - \\
\hline \multirow[t]{3}{*}{ Progesterone receptor } & Positive & 578 & 290 & 1.00 & 742 & 241 & 1.00 \\
\hline & Negative & 199 & 79 & $0.71(0.48-1.08)$ & 237 & 56 & $0.79(0.50-1.23)$ \\
\hline & Unknown & 111 & 5 & $4.15(0.31-54.96)$ & 14 & - & - \\
\hline \multirow[t]{3}{*}{ HER-2 } & Negative & 630 & 292 & 1.00 & 411 & 131 & 1.00 \\
\hline & Positive & 77 & 44 & $1.04(0.66-1.64)$ & 97 & 22 & $0.63(0.37-1.10)$ \\
\hline & Unknown & 181 & 38 & $0.93(0.59-1.50)$ & 485 & 144 & $1.04(0.77-1.42)$ \\
\hline \multirow[t]{3}{*}{ Multifocality } & No & 452 & 194 & 1.00 & 732 & 192 & 1.00 \\
\hline & Yes & 93 & 71 & $1.58(1.07-2.32)$ & 115 & 73 & $2.21(1.50-3.23)$ \\
\hline & Unknown & 343 & 109 & $0.72(0.53-0.99)$ & 146 & 32 & $0.88(0.56-1.40)$ \\
\hline \multirow[t]{3}{*}{ Vascular invasion } & No & 148 & 41 & 1.00 & 908 & 227 & 1.00 \\
\hline & Yes & 18 & 34 & $6.10(2.98-12.50)$ & 69 & 63 & $3.04(2.03-4.57)$ \\
\hline & Unknown & 722 & 299 & $1.64(1.10-2.44)$ & 16 & 7 & $1.80(0.66-4.93)$ \\
\hline
\end{tabular}

and they may suffer from complications regardless of the type of surgery performed, i.e., SNB or ALND [9]. However, the incidence of $\mathrm{SN}$ metastasis has been reported to be $33.2 \%$ in invasive breast cancer [21].

SNB has been used as standard method for the assessment of axillary status since the early 2000s, and usually, a SNB will be followed by an axillary dissection in case of SN metastases, but for the last 5 years and in recent publications, ALND has been questioned in patients with metastatic $\mathrm{SN}$ due to the encouraging survival results for patient not undergoing axillary surgery [22]. This has led to calls for more conservative management 
of the axilla in early breast cancer, and there is still continued debate about the role of axillary dissection in this patient population [23].

In this study, we observed that tumor size is an independent predictive factor for positive $\mathrm{SN}$ status, where SN metastases were observed in 367 patients with T1 (24.3\%). Capdet et al. showed in a study involving 1416 patients that SN metastases were detected in 368 patients (26\%) with T1 cancer, and young age, tumor size and location, histological type, histological grade, and lymph vascular invasion appeared to be significant risk factors of SN involvement [24]. Viale et al. showed in a study involving more than 4000 patients that tumor size and peritumoral vascular invasion emerged as the most powerful independent predictors for SN metastases [21].

In our study, the risk of $\mathrm{SN}$ metastases was not influenced by histological grade (Table 2); other studies have shown that the risk of SN metastases increased not only depending on tumor size but also on the histological grade and the patient age. Mustafa et al. showed in a study involving more than 2000 patients with T1 tumors that histological grades II-III in women before the age of 40 years had higher incidence of sentinel node involvement compared with histological grade I [25].

We observed in this study that the risk of SN involvement was low in tumors of rare type, e.g., medullary breast cancer. However, all rare tumors were merged in one sub-group in this study as these types were rare and separate analyses were difficult due to poor statistical power (Table 2).

We observed in our study that the strongest independent predictor of $\mathrm{SN}$ involvement was lymphovascular invasion (3.74; 2.66-5.27) followed by, in order of significance, size of the tumor $(2.56 ; 1.07-6.09)$ and multifocality (1.90; $1.45-2.47)$, while Gajdos et al. showed in a study which involved 850 consecutive patients who underwent ALND for T1 breast cancer that axillary lymph node metastases were most significantly related to lymphatic invasion in the primary tumor, followed by tumor size and patient age [26]. Yoshihara et al. has showed in their evaluation of 1300 patients that lymphovascular invasion and tumor size emerged as the most powerful independent predictors of ALN metastases, followed by the location of the tumor in the breast and the presence of multiple foci [27]. However, the usefulness of lymphovascular involvement in decision making before surgery is of limited clinical value as this factor is not known until the final pathological report is available.

Mammography screening for breast cancer becomes more prevalent; improvements in imaging and new techniques make breast tumors easier to be found at smaller sizes than before [28]. In this study, we observed that breast cancer which is detected by mammography screening had lower risk for metastatic involvement of the sentinel nodes.
This is probably due to many different factors but most possibly because of early detection of invasive tumors with small size less than $10 \mathrm{~mm}$ which is in turn associated with lower risk for $\mathrm{SN}$ metastases.

The possibility of metastatic involvement of $\mathrm{SN}$ in breast cancer with negative hormonal status particularly estrogen receptor status has not been established clearly compared with receptor-positive tumor. Our findings indicate that the risk of $\mathrm{SN}$ metastases is low in tumors with negative hormonal status for estrogen $(0.64$; $0.42-$ 0.99). Mattes et al. observed in their study including 7274 patients with T1-T3 infiltrating ductal cancer that HR-/HER2 - cancers had a significantly lower risk (OR 0.686 ) of nodal positivity than the HR+/HER2 - subtype [29]. Similarly has Ugras et al. showed in their study involving 11,596 patients that nodal metastases were least frequent in triple negative (TN) cancers compared with other subtypes [30].

The results of this study showed that it is possible to identify patients with invasive breast cancer with a high risk of metastatic involvement of the sentinel nodes. This knowledge is useful in clinical practice and it might help in order to improve planning for surgical or systemic therapy. Furthermore, this study might help in identifying patients with a high probability of node-negative tumor where the SN procedure may possibly be omitted, although it is still very difficult to identify and select cases defiantly as the most powerful predictors for metastases to $\mathrm{SN}$ according to many studies are those which are available after histopathological examination such as lymphovascular invasion.

\section{Conclusions}

We conclude that $\mathrm{SN}$ metastasis is less likely to occur in women with invasive breast cancer diagnosed by screening mammogram and in tumors with negative estrogen status. Tumors larger than $20 \mathrm{~mm}$, multifocality, or lymphovascular invasion are also factors associated with higher risk for SN metastases.

\section{Abbreviations}

ALND: Axillary lymph node dissection; Cl: Confidence interval; FISH: Fluorescent in situ hybridization; HER2: Human epidermal growth factor receptor 2;

HR: Hormone receptor; IHC: Immunohistochemistry; INCA: Information Network for Cancer Care; ITC: Isolated tumor cell; LU-Dnr: Lund document number; NHG: Nottingham histological grading; OR: Odds ratio; RCC-Syd: Regional Cancer Center in Southern Sweden; SN: Sentinel node; SNB: Sentinel node biopsy; SPSS: Statistical Package for the Social Sciences; TN: Triple negative; TNM: Tumor lymph node metastasis; WHO: World Health Organization

\section{Acknowledgements}

Not applicable

\section{Funding}

This study was supported by The Gunnar Nilsson Cancer Foundation, the Ernhold Lundström Foundation, the Einar and Inga Nilsson Foundation, Malmö University Hospital Cancer Research Fund, Skåne University Hospital Funds and Donations, the Breast Cancer Network at Lund University and Region Skåne (ALF), and Central Hospital of Kristianstad (CSK). 


\section{Availability of data and materials}

The data that support the findings of this study are available from INCA but restrictions apply to the availability of these data, which were used under license for the current study, and so are not publicly available. Data are however available from the authors upon reasonable request and with permission of INCA.

\section{Authors' contributions}

All authors were involved in drafting the manuscript or revising it critically for important intellectual content and approved the final manuscript.

\section{Ethics approval and consent to participate}

The present study was approved by the Ethic Committee at Lund University, Lund, Sweden. (LU-Dnr 2013/821).

\section{Consent for publication}

Not applicable

\section{Competing interests}

The authors declare that they have no competing interests.

\section{Publisher's Note}

Springer Nature remains neutral with regard to jurisdictional claims in published maps and institutional affiliations.

\author{
Author details \\ 'Department of Surgery, Central Hospital of Kristianstad, SE-291 85 \\ Kristianstad, Sweden. ${ }^{2}$ Department of Clinical Sciences Malmö, Lund \\ University, Malmö, Sweden. ${ }^{3}$ Department of Surgery, Skåne University \\ Hospital, Malmö, Sweden. ${ }^{4}$ Department of Clinical Sciences Lund, Lund \\ University, Lund, Sweden.
}

\section{Received: 21 September 2017 Accepted: 27 February 2018} Published online: 12 March 2018

\section{References}

1. Giuliano AE, Kirgan DM, Guenther JM, Morton DL. Lymphatic mapping and sentinel lymphadenectomy for breast cancer. Ann Surg. 1994;220(3):391-8.

2. Luini A, Gatti G, Ballardini B, Zurrida S, Galimberti V, Veronesi P, Vento AR, Monti S, Viale G, Paganelli G, Veronesi U. Development of axillary surgery in breast cancer. Ann Oncol. 2005;16(2):259-62.

3. Giuliano AE, Hunt KK, Karla V, Ballman KV, et al. Axillary dissection vs no axillary dissection in women with invasive breast cancer and sentinel node metastasis: a randomized clinical trial. JAMA. 2011;305(6):569-75.

4. Tvedskov TF, Jensen MB, Ejlertsen B, Christiansen P, Balslev E, Kroman N. Prognostic significance of axillary dissection in breast cancer patients with micro metastases or isolated tumor cells in sentinel nodes: a nationwide study. Breast Cancer Res Treat. 2015;153(3):599-606.

5. Marrazzo A, Boscaino G, Marrazzo E, Taormina P, Toesca A. Breast cancer subtypes can be determinant in the decision making process to avoid surgical axillary staging: a retrospective cohort study. Int J Surg. 2015;21:156-61.

6. Majid S, Tengrup I, Manjer J. Clinical assessment of axillary lymph nodes and tumor size in breast cancer compared with histopathological examination: a population-based analysis of 2,537 women. World J Surg. 2013;37(1):67-71.

7. Schipper RJ, van Roozendaal LM, de Vries B, Pijnappel RM, Beets-Tan RG, Lobbes MB, Smidt ML. Axillary ultrasound for preoperative nodal staging in breast cancer patients: is it of added value? Breast. 2013;22(6):1108-13.

8. Lucci A, McCall LM, Beitsch PD, Whitworth PW, Reintgen DS, Blumencranz PW, Leitch AM, Saha S, Hunt KK, Giuliano AE. Surgical complications associated with sentinel lymph node dissection (SLND) plus axillary lymph node dissection compared with SLND alone in the American College of Surgeons Oncology Group Trial Z0011. J Clin Oncol. 2007;25(24):3657-63.

9. Sackey H, Magnuson A, Sandelin K, Liljegren G, Bergkvist L, Fülep Z, Celebioglu F, Frisell J. Arm lymphoedema after axillary surgery in women with invasive breast cancer. Br J Surg. 2014;101(4):390-7.

10. Sackey H, Johansson H, Sandelin K, Liljegren G, MacLean G, Frisell J, Brandberg Y. Self-perceived, but not objective lymphoedema is associated with decreased long-term health-related quality of life after breast cancer surgery. Eur J Surg Oncol. 2015;41(4):577-84.

11. Giuliano AE, McCall L, Beitsch P, Whitworth PW, Blumencranz P, Leitch AM, Saha S, Hunt KK, Morrow M, Ballman K. Locoregional recurrence after sentinel lymph node dissection with or without axillary dissection in patients with sentinel lymph node metastases. Ann Surg. 2016;264(3):413-20.

12. Barry JM, Weber WP, Sacchini V. The evolving role of axillary lymph node dissection in the modern era of breast cancer management. Surg Oncol. 2012;21(2):143-5.

13. TNM classification of malignant tumours, Available as download from https://cancerstaging.org/references-tools/Pages/What-is-Cancer-Staging. aspx. Accessed 1 Sept 2017.

14. World Health Organisation, www.who.org, available as download from http://publications.iarc.fr/Book-And-Report-Series/Who-larc-Classification-OfTumours/Who-Classification-Of-Tumours-Of-The-Breast-2012. Accessed 20 June 2017.

15. American Cancer Society, available as download from http://www.cancer. org/cancer/breastcancer/detailedguide/breast-cancer-classifying. Accessed 20 June 2017.

16. Breast cancer and breast pathology, Available as download from http:// pathology.jhu.edu/breast/grade.php. Accessed 30 July 2017.

17. Swedish society of pathology, KVAST, Available as download from http:// www.svfp.se/brostpatologi. Accessed 1 Sept 2017.

18. American Joint Committee on Cancer (AJCC). In: Amin MB, Edge SB, Greene FL, et al. editors. Cancer staging manual. 8th ed. Chicago: Springer; 2017.

19. Rydén L, Haglund M, Bendahl PO, Hatschek T, Kolaric A, Kovács A, Olsson A, Olsson H, Strand C, Fernö M; Swedish Her2 Analysis Group. Reproducibility of human epidermal growth factor receptor 2 analysis in primary breast cancer: a national survey performed at pathology departments in Sweden. Acta Oncol. 2009:48(6):860-6.

20. National Breast Cancer Register. Available as download from http://www. cancercentrum.se/samverkan/cancerdiagnoser/brost/kvalitetsregister/. Accessed 20 June 2017

21. Viale G, Zurrida S, Maiorano E, Mazzarol G, Pruneri G, Paganelli G, Maisonneuve P, Veronesi U. Predicting the status of axillary sentinel lymph nodes in 4351 patients with invasive breast carcinoma treated in a single institution. Cancer. 2005:103(3):492-500.

22. Grabau D, Dihge L, Fernö M, Ingvar C, Rydén L. Completion axillary dissection can safely be omitted in screen detected breast cancer patients with micrometastases. A decade's experience from a single institution. Eur J Surg Oncol. 2013;39(6):601-7.

23. de Boniface J, Frisell J, Bergkvist L, Andersson Y. Swedish Breast Cancer Group and the Swedish Society of Breast Surgery. Ten-year report on axillary recurrence after negative sentinel node biopsy for breast cancer from the Swedish Multicentre Cohort Study. Br J Surg. 2017;104(3):238-47.

24. Capdet J, Martel P, Charitansky H, Lim YK, Ferron G, Battle L, Landier A, Mery E, Zerdoub S, Roche H, Querleu D. Factors predicting the sentinel node metastases in $\mathrm{T} 1$ breast cancer tumor: an analysis of 1416 cases. Eur J Surg Oncol. 2009;35(12):1245-9.

25. Mustafa IA, Cole B, Wanebo HJ, Bland KI, Chang HR. The impact of histopathology on nodal metastases in minimal breast cancer. Arch Surg. 1997:132(4):384-90.

26. Gajdos C, Tartter PI, Bleiweiss IJ. Lymphatic invasion, tumor size, and age are independent predictors of axillary lymph node metastases in women with T1 breast cancers. Ann Surg. 1999;230(5):692-6.

27. Yoshihara E, Smeets A, Laenen A, Reynders A, Soens J, Van Ongeval C, Moerman P, Paridaens R, Wildiers H, Neven P, Christiaens MR. Predictors of axillary lymph node metastases in early breast cancer and their applicability in clinical practice. Breast. 2013;22(3):357-61.

28. Destounis SV, Morgan R, Arieno A. Screening for dense breasts: digital breast tomosynthesis. AJR Am J Roentgenol. 2015;204(2):261-4.

29. Mattes MD, Bhatia JK, Metzger D, Ashamalla H, Katsoulakis E. Breast cance subtype as a predictor of lymph node metastasis according to the SEER Registry. J Breast Cancer. 2015;18(2):143-8.

30. Ugras S, Stempel M, Patil S, Morrow M. Estrogen receptor, progesterone receptor, and HER-2 status predict lymphovascular invasion and lymph node involvement. Ann Surg Oncol. 2014;21(12):3780-6. 